\title{
Association between education and quality of diabetes care in Switzerland
}

This article was published in the following Dove Press journal:

International Journal of General Medicine

25 February 2015

Number of times this article has been viewed

\author{
Aline Flatz \\ Alejandra Casillas \\ Silvia Stringhini \\ Emilie Zuercher \\ Bernard Burnand \\ Isabelle Peytremann- \\ Bridevaux \\ Institute of Social and Preventive \\ Medicine, Lausanne University \\ Hospital, Lausanne, Switzerland
}

Correspondence: Aline Flatz Institute of Social and Preventive

Medicine, Lausanne University Hospital,

Route de la Corniche I0,

1010 Lausanne, Switzerland

Tel +4I 446346316

Fax $+4 \mid$ II $3 \mid 44954$

Email aline.flatz@chuv.ch
Purpose: Low socioeconomic status is associated with higher prevalence of diabetes, worse outcomes, and worse quality of care. We explored the relationship between education, as a measure of socioeconomic status, and quality of care in the Swiss context.

Patients and methods: Data were drawn from a population-based survey of 519 adults with diabetes during fall 2011 and summer 2012 in a canton of Switzerland. We assessed patients and diabetes characteristics. Eleven indicators of quality of care were considered (six of process and five of outcomes of care). After bivariate analyses, regression analyses adjusted for age, sex, and diabetic complications were performed to assess the relationship between education and quality of care.

Results: Of 11 quality-of-care indicators, three were significantly associated with education: funduscopy (patients with tertiary versus primary education were more likely to get the exam: odds ratio, 1.8; 95\% confidence interval [CI], 1.004-3.3) and two indicators of health-related quality of life (patients with tertiary versus primary education reported better health-related quality of life: Audit of Diabetes-Dependent Quality of Life: $\beta=0.6$ [95\% CI, 0.2-0.97]; SF-12 mean physical component summary score: $\beta=3.6$ [95\% CI, 0.9-6.4]).

Conclusion: Our results suggest the presence of educational inequalities in quality of diabetes care. These findings may help health professionals focus on individuals with increased needs to decrease health inequalities.

Keywords: primary care, education, quality of care, diabetes

\section{Introduction}

Diabetes and many other chronic diseases show a higher prevalence among groups of low socioeconomic status (SES). ${ }^{1,2}$ In addition, patients with diabetes and a low SES have been shown to present with worse health outcomes such as poorer glycemic control, more diabetes-related complications, higher cardiovascular risk factors, and poorer self-rated health. ${ }^{3-7}$

A model has been proposed by Brown et $\mathrm{al}^{8}$ to explain this association between SES and health outcomes in patients with diabetes. It suggests that health outcomes (which show the effects of care on the health status of patients ${ }^{9}$ ) are influenced by distal factors, such as individual (eg, cultural background) or community characteristics, as well as by more proximal factors such as health behaviors, access to health care, and processes of care (ie, what is done to care for a patient). Most studies looking at the relationship between SES and processes of diabetes care reported worse processes of care among patients of lower SES. ${ }^{10,11}$ It is well accepted that processes of care influence diabetes outcomes, and many processes are considered indicators of quality 
of diabetes care. Thus, achieving optimal processes of care is postulated to be a key element in the care of patients with diabetes.

In Switzerland, health insurance is mandatory, and access to care is universal. Despite that, health inequalities across SES groups have been reported, mostly for mortality and cardiovascular risk factors. ${ }^{12}$ Moreover, recent studies have shown that individuals with low income were at high risk of foregoing healthcare for economic reasons, ${ }^{13}$ possibly because of the high out-of-pocket payments characterizing the Swiss health care system. However, it remains unknown whether once individuals have reached the health care system, social inequalities persist with regard to quality of care. Indeed, no study in Switzerland has so far examined the relationship between education and quality of care in any disease.

The aim of this study was to determine the association between education and quality of care among patients with diabetes.

\section{Material and methods}

\section{Setting and patients}

We used data from a cross-sectional paper survey, selfadministered among a cohort of patients with any type of diabetes, living in the canton of Vaud, a large French-speaking region in Switzerland with more than 720,000 inhabitants. Adults (aged $\geq 18$ years) presenting with a prescription for insulin, oral antidiabetics, glycemic strips, or a glucose meter were recruited by pharmacists in fall 2011 and summer 2012. Fifty-six of the 140 randomly contacted pharmacies agreed to participate. Although pharmacists checked the eligibility of the patients and presented the study, patients willing to participate were asked to fill in the questionnaire at home and send it back to the investigators. Patients with an obvious cognitive impairment, those who did not speak or understand French well enough, those who did not reside in the canton of Vaud, and women with gestational diabetes were excluded. With patients' approvals, treating physicians were contacted and asked to fill in a brief questionnaire to collect some laboratory and clinical data. The final sample totaled 519 patients (406 from 1,013 eligible patients in 2011 and 113 from 328 eligible patients in 2012, corresponding to participation rates of $40 \%$ and $34 \%$, respectively). The data collection process is described in more detail elsewhere. ${ }^{14}$

This study complies with the current laws of Switzerland. Ethical approval was received from the Cantonal Ethics Committee of Research on the Human Being (protocol 151/11).

\section{Measures}

The variables considered in this study included one exposure variable, several dependent variables, and other independent variables considered as potential confounders.

\section{Education}

The exposure variable was self-reported education, which is one of several dimensions of socioeconomic status. It was grouped into three categories according to the International Standard Classification of Education: primary education, corresponding to the completion of compulsory school or less; secondary education, corresponding to vocational training or high school; and tertiary education, corresponding to university or technical college.

\section{Processes of care (dependent variables)}

Patients were asked whether they had received the following processes of care during the last 12 months: $\mathrm{HbA}_{1 \mathrm{c}}$ level check (yes, one time; yes, more than one time; no; or I do not know), lipid blood test (yes, no, or I do not know), microalbuminuria test (yes, no, or I do not know), funduscopy (yes, less than 1 year ago; yes, 1-2 years ago; yes, more than 2 years ago; never; or I do not know), feet examined by a physician (yes, no, or I do not know), and influenza vaccination (yes, no, or I do not know). We coded these variables into two categories: patients having received at least one check versus those not having received a check. We also regrouped "do not know" answers into the missing answer category. For the $\mathrm{HbA}_{1 \mathrm{c}}$ variable, we only considered the answers of patients reporting knowing the meaning of $\mathrm{HbA}_{1 \mathrm{c}}$ (skip question).

\section{Outcomes of care (dependent variables)}

Most outcomes of care considered were reported by the treating physicians (162 physicians reported the values of 271 patients, for a physicians' participation rate of $60 \%$ in 2011 and 63\% in 2012). Physicians' reported values were the following: last measured value of $\mathrm{HbA}_{1 \mathrm{c}}(\%)$, systolic blood pressure $(\mathrm{mmHg})$, and low-density lipoprotein cholesterol $(\mathrm{mmol} / \mathrm{L})$. We also considered patient-reported health-related quality of life (HRQoL), as measured by two indicators: a disease-specific measure, the Audit of Diabetes-Dependent Quality of Life, ${ }^{15}$ with values ranging between -9 (maximum negative effect of diabetes) and +3 (maximum positive effect of diabetes), and a generic instrument, the SF-12. ${ }^{16}$ The results of the SF-12 are expressed with two scores: the mental component summary and physical component summary scores, with each having been initially constructed so as to present a mean of 50 and a standard deviation of 50 
Table I Descriptive analyses

\begin{tabular}{|c|c|c|}
\hline Characteristics of participants & $\mathbf{N}$ & \\
\hline Women & 519 & $40.3 \%$ \\
\hline Mean age, years (standard deviation) & 519 & $64.5(11.3)$ \\
\hline Diabetes type 2 & 480 & $72.3 \%$ \\
\hline Mean household income per month, Swiss francs & 451 & \\
\hline$<3,499$ & & $21.2 \%$ \\
\hline $3,500-5,499$ & & $26.5 \%$ \\
\hline $5,500-9,499$ & & $27.8 \%$ \\
\hline$>9,500$ & & $17.3 \%$ \\
\hline Education & 504 & \\
\hline Primary & & $18.9 \%$ \\
\hline Secondary & & $56.2 \%$ \\
\hline Tertiary & & $25.0 \%$ \\
\hline Participated in a diabetes management course & 507 & \\
\hline Yes, $>2$ years ago & & $22.3 \%$ \\
\hline Yes, $\leq 2$ years ago & & $10.5 \%$ \\
\hline $\begin{array}{l}\text { Visited the GP at least once during the last } \\
12 \text { months }\end{array}$ & 473 & $93.7 \%$ \\
\hline At least one diabetes complication & 505 & $47.5 \%$ \\
\hline Processes of care & & \\
\hline Received $\mathrm{HbA}_{\mathrm{Ic}}$ check last year* & 280 & $98.9 \%$ \\
\hline Received lipid check last year & 500 & $96.6 \%$ \\
\hline Received microalbuminuria check last year & 436 & $74.3 \%$ \\
\hline Received funduscopy last year & 503 & $59.1 \%$ \\
\hline Received feet examination last year & 506 & $67.0 \%$ \\
\hline Received influenza vaccination last year & 513 & $63.9 \%$ \\
\hline Outcomes of care & & \\
\hline Mean last $\mathrm{HbA}_{\mathrm{Ic}}$ value, \% (standard deviation) ${ }^{+}$ & 268 & $7.2(1.2)$ \\
\hline $\begin{array}{l}\text { Mean systolic blood pressure value, } \\
\mathrm{mmHg} \text { (standard deviation) })^{+}\end{array}$ & 270 & $133.6(15.7)$ \\
\hline Mean LDL value, $\mathrm{mmol} / \mathrm{L}$ (standard deviation) ${ }^{+}$ & 242 & $2.6(0.9)$ \\
\hline SF-12 & & \\
\hline $\begin{array}{l}\text { Mean physical component summary } \\
\text { score (standard deviation) })^{\ddagger}\end{array}$ & 498 & $43.4(10.5)$ \\
\hline $\begin{array}{l}\text { Mean mental component summary } \\
\text { score (standard deviation) })^{\pi}\end{array}$ & 496 & $47.0(11.2)$ \\
\hline $\begin{array}{l}\text { Audit of Diabetes-Dependent Quality of Life, } \\
\text { mean score (standard deviation) }\end{array}$ & 512 & $-1.6(1.6)$ \\
\hline
\end{tabular}

Notes: *Among patients who know what $\mathrm{HbA}_{\mathrm{Ic}}$ means; ${ }^{+}$physician-reported values (a total of 162 physicians reported the values of 27 I patients); ${ }^{\ddagger}$ physical component summary; "Tmental component summary.

Abbreviations: GP, general practitioner; $\mathrm{HbA}_{\mathrm{Ic}}$, glycosylated hemoglobin; LDL, low-density lipoprotein; SF-12, I2-item Short Form Health Survey.

in the US population, and with each presenting a clinically significant cut-off of $5 .{ }^{17}$ Throughout the manuscript, HRQoL refers to both Audit of Diabetes-Dependent Quality of Life and SF-12, unless otherwise stated.

\section{Other independent variables}

Further covariates considered were age, sex, and the presence (yes/no) of diabetes-related complications (cardiovascular disease, stroke, vision problems not including cataracts or glaucoma, chronic kidney insufficiency, dialysis or kidney transplantation, foot neuropathy, foot ulcer, amputation of a lower limb, and severe hypo- or hyperglycemia).

\section{Statistical analyses}

Bivariate analyses were first carried out between education and dependent variables (processes and outcomes of care), using chi square test and analysis of variance for categorical and continuous variables, respectively. We further built linear and logistic regression models to assess the association between education and processes and outcomes of care, respectively. We adjusted all final models for age, sex, and the presence of diabetes-related complications, variables considered to be potential confounders of the association of interest. To take into account the intragroup correlation (clusters of pharmacies), the clustered sandwich estimator was used to estimate the variance-covariance matrix. Analyses were performed using Stata 12.1. $P$ values $<0.05$ were considered statistically significant.

\section{Results}

The study participants had a mean age of 64.5 years, $40.3 \%$ were women, and $47.5 \%$ had at least one diabetes complication. Educational status distribution was as follows: $18.9 \%$ primary, $56.2 \%$ secondary, and $25.0 \%$ tertiary education (Table 1). In bivariate analyses (Tables 2 and 3), the proportion of patients having received feet examination grew from primary to tertiary education, with a statistically significant trend. Bivariate analyses of outcomes of care showed that diabetes-specific and generic quality-of-life measures significantly increased with increasing educational level.

Fully adjusted regressions showed a general pattern of higher quality of care among patients with higher educational levels (Table 4). Funduscopy was the only process of care significantly associated with education: patients with tertiary education were more likely to receive a funduscopy

Table 2 Proportion of participants who received diabetes-related checks by level of education

\begin{tabular}{lllllll}
\hline $\begin{array}{l}\text { Processes } \\
\text { of care }\end{array}$ & $\begin{array}{l}\mathbf{H b A}_{\mathrm{lc}} \\
\text { check* }\end{array}$ & $\begin{array}{l}\text { Lipid } \\
\text { check }\end{array}$ & $\begin{array}{l}\text { Microalbuminuria } \\
\text { check }\end{array}$ & Funduscopy & $\begin{array}{l}\text { Feet } \\
\text { examination }^{+}\end{array}$ & $\begin{array}{l}\text { Influenza } \\
\text { vaccination }\end{array}$ \\
\hline Education & $\mathrm{n}=326$ & $\mathrm{n}=486$ & $\mathrm{n}=422$ & $\mathrm{n}=489$ & $\mathrm{n}=492$ & $\mathrm{n}=498$ \\
Primary, \% & 96.3 & 96.6 & 75.3 & 51.1 & 59.3 & 59.1 \\
Secondary, \% & 98.9 & 97.5 & 74.3 & 61.9 & 65.9 & 64.8 \\
Tertiary, \% & 98.8 & 96.8 & 73.1 & 60.3 & 73.6 & 66.1 \\
\hline
\end{tabular}

Notes: *Among patients who know what $\mathrm{HbA}_{\mathrm{lc}}$ means; ${ }^{+} P$ value for trend $<0.05$.

Abbreviation: $\mathrm{HbA}_{\mathrm{lc}}$, glycosylated hemoglobin. 
Table 3 Mean values of outcomes of care by level of education

\begin{tabular}{|c|c|c|c|c|c|c|}
\hline $\begin{array}{l}\text { Outcomes } \\
\text { of care }\end{array}$ & $\begin{array}{l}\text { Last } \mathrm{HbA}{ }_{\mathrm{lc}} \\
\text { value, } \% \\
{[\mathrm{mmol} / \mathrm{mol}]^{*}}\end{array}$ & $\begin{array}{l}\text { Systolic blood } \\
\text { pressure, } \\
\mathrm{mmHg}^{*}\end{array}$ & $\begin{array}{l}\text { LDL, } \\
\text { mmol* }\end{array}$ & $\begin{array}{l}\text { SF-12, mean } \\
\text { physical component } \\
\text { summary score }\end{array}$ & 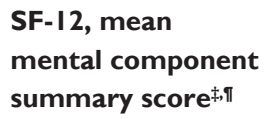 & $\begin{array}{l}\text { Audit of diabetes- } \\
\text { dependent quality } \\
\text { of life: mean score }\end{array}$ \\
\hline Education & $n=259$ & $n=26 I$ & $n=233$ & $\mathrm{n}=486$ & $\mathrm{n}=485$ & $\mathrm{n}=50 \mathrm{I}$ \\
\hline Primary & 7.1 [54] & 132.8 & 2.6 & 41.0 & 45.0 & -2.0 \\
\hline Secondary & $7.2[55]$ & 135.1 & 2.6 & 43.3 & 47.0 & -1.4 \\
\hline Tertiary & $7.3[56]$ & 130.3 & 2.6 & 45.4 & 48.1 & -1.5 \\
\hline
\end{tabular}

Notes: *Physician-reported values (a total of 162 physicians reported the values of 271 patients); ${ }^{+}$physical component summary; ${ }^{\ddagger} p$ value for trend $<0.05 ;{ }^{\pi} m e n t a l$ component summary.

Abbreviations: $\mathrm{HbA}_{\mathrm{Ic}}$, glycosylated hemoglobin; LDL, low-density lipoprotein; SF-12, 12 -item Short Form Health Survey.

than those with primary education (odds ratio, $1.8 ; 95 \%$ confidence interval, 1.004-3.3). Analyses of outcome variables showed that only HRQoL was significantly associated with education. In fact, patients with secondary and tertiary education had a higher quality of life, as measured by the Audit of Diabetes-Dependent Quality of Life and the physical component summary score of the SF-12 compared with patients with primary education.

\section{Discussion}

This study suggests the presence of social inequalities in the care of patients with diabetes, even in a wealthy country with universal health insurance coverage. More specifically, we found educational disparities for one process of care (funduscopy) and HRQoL.

\section{Processes of care}

Our results are consistent with most studies assessing the relationship between SES and processes of diabetes care, which report, with few exceptions, ${ }^{18,19}$ an association between lower SES and worse processes of care. Indeed, low SES has been associated with worse diabetes education ${ }^{20}$ and poorer use of annual medical checks. ${ }^{2,7,11,21}$ A direct comparison to these findings is, however, rather difficult, as almost every study selected different sets of processes and outcomes of care. Our results nevertheless remain consistent with the literature, insofar as funduscopy is the process of care that has been most often related to lower SES. ${ }^{10,21}$ This may be explained by the fact that this exam has to be performed by a specialist, unlike the other considered processes of care. In fact, a better-educated patient may be more likely to get an appointment directly with a specialist or to remind his general practitioner to refer him. Further, such a patient may also better understand what was done and better self-report the exam. Finally, our other processes of care share a feature that may explain their lack of association with education: they are all routinely performed and can all be performed in a general practitioner's practice.

\section{Outcomes of care}

In line with other research, we also found that patients with lower education reported lower diabetes-specific and generic

Table 4 Association between education and quality of care, adjusted for age, sex, and the presence of diabetes-related complications

\begin{tabular}{|c|c|c|c|}
\hline & Primary education & Secondary education & Tertiary education \\
\hline \multicolumn{4}{|l|}{ Processes of care, odds ratio ( $95 \%$ confidence interval) } \\
\hline $\mathrm{HbA}_{\mathrm{Ic}}$ check* $^{*}$ & Ref & $5.6(0.3-102.3)$ & $5.4(0.3-99.7)$ \\
\hline Lipid check & Ref & $\mathrm{I} .4(0.4-5.5)$ & $1.2(0.3-5.9)$ \\
\hline Microalbuminuria check & Ref & $0.8(0.5-1.5)$ & $0.7(0.4-1.5)$ \\
\hline Funduscopy & Ref & $1.6(0.96-2.6)$ & $1.8(1.004-3.3)^{\S}$ \\
\hline Feet examination & Ref & $1.2(0.8-2.0)$ & $1.8(0.96-3.3)$ \\
\hline Influenza vaccination & Ref & $1.3(0.8-2.2)$ & $\mathrm{I} .5(0.8-2.7)$ \\
\hline \multicolumn{4}{|l|}{ Outcomes of care, $\beta$ ( $95 \%$ confidence interval) } \\
\hline Mean last $\mathrm{HbA}_{\mathrm{Ic}}$ value $(\%)^{+}$ & Ref & $0.1(-0.3$ to 0.7$)$ & $0.2(-0.3$ to 0.7$)$ \\
\hline Mean systolic blood pressure value, $\mathrm{mmHg}^{+}$ & Ref & $-2.4(-7.1$ to 2.2$)$ & $-3.4(-8.8$ to 2.1$)$ \\
\hline Mean $\mathrm{LDL}$ value $(\mathrm{mmol} / \mathrm{l})^{+}$ & Ref & $0.002(-0.3 \text { to } 0.3)^{\S}$ & $0.1(-0.3$ to 0.5$)$ \\
\hline \multicolumn{4}{|l|}{ SF-12 } \\
\hline Mean physical component summary score s $^{\ddagger}$ & Ref & $2.5(0.2-4.8)^{\S}$ & $3.6(0.9-6.4)^{\S}$ \\
\hline Mean mental component summary score ${ }^{\pi}$ & Ref & $1.8(-0.8$ to 4.5$)$ & $2.6(-0.5$ to 5.7$)$ \\
\hline Audit of Diabetes-Dependent Quality of Life (mean score) & Ref & $0.6(0.3-0.97)^{\S}$ & $0.6(0.2-0.97)^{\S}$ \\
\hline
\end{tabular}

Notes: *Among patients who know what $\mathrm{HbA}_{\mathrm{lc}}$ means; ${ }^{+}$physician-reported values (a total of 162 physicians reported the values of $27 \mathrm{I}$ patients); ${ }^{\ddagger}$ physical component summary; ${ }^{\top}$ mental component summary; ${ }^{\S P}<0.05$.

Abbreviations: $\mathrm{HbA}_{\mathrm{Ic}}$, glycosylated hemoglobin; LDL, low-density lipoprotein; SF-12, 12 -item Short Form Health Survey. 
HRQoL. ${ }^{22,23}$ Our hypothesis is that a better education may contribute to increased HRQoL through better understanding of the nature of the disease, better coping with the disease, and eventually better diabetes care overall. Most of these associations were, however, not clinically significant.

The population-based design and the use of many processes and outcomes of care are the main strengths of this study. Yet our findings have limitations, with one issue being the selection bias resulting from a moderate participation rate and recruitment of patients in pharmacies. However, this is more likely to have introduced an underestimation than an overestimation of the association between education and quality of care by excluding individuals of the lowest socioeconomic groups. Indeed, individuals not proficient in French were excluded at enrollment, and a prerequisite to study participation was a visit to the pharmacy. These individuals (of low SES) are also more difficult to recruit for studies. ${ }^{24}$ In our study, people of lower SES may have visited a pharmacy less often than more wealthy individuals, and thus may have been less likely to be recruited. However, we are confident that our population sample is representative, as some characteristics of our study patients were similar to those of a prior study conducted in the same region. ${ }^{25}$ Another limitation was the sample size, which was not planned for the objective of the present analysis. As a possible consequence, we may not have had enough power to always detect statistically significant differences, despite suggestive and consistent trends toward SES inequalities in quality of care. Finally, self-reported data are prone to recall bias, which may have affected our process and outcome measures.

\section{Conclusion}

Achieving good quality of care is essential for individuals with diabetes, as it can decrease their mortality and morbidity risks. Recent studies have shown that tailored interventions for socially disadvantaged patients can have positive effects on diabetes care and that health inequalities may disappear after educational interventions. ${ }^{6}$ Thus, interventions specifically targeting these groups of patients may have the potential to reduce social inequalities in health and should be among the priorities of diabetes management programs.

\section{Acknowledgment}

We thank Katia Iglesias Rutishauser for statistical assistance.

\section{Funding}

The project was funded by the Department of Public Health of the canton of Vaud ("Programme cantonal Diabète"). I.P.-B. was supported by a grant from the Swiss National
Science Foundation (PROSPER Grant 32333B-123817 and Grant 32333B-139789) and, since August 2013, has been supported by a grant from the Swiss School of Public Health (SSPH + Assistant Professorship grant).

\section{Disclosure}

The authors report no conflicts of interest in this work.

\section{References}

1. Klijs B, Nusselder WJ, Looman CW, Mackenbach JP. Educational disparities in the burden of disability: contributions of disease prevalence and disabling impact. Am J Public Health. 2014;104(8): e141-e148.

2. Korda RJ, Paige E, Yiengprugsawan V, Latz I, Friel S. Income-related inequalities in chronic conditions, physical functioning and psychological distress among older people in Australia: cross-sectional findings from the 45 and up study. BMC Public Health. 2014;14(1):741.

3. Do YK, Eggleston KN. Educational disparities in quality of diabetes care in a universal health insurance system: evidence from the 2005 Korea National Health and Nutrition Examination Survey. Int J Qual Health Care. 2011;23(4):397-404.

4. Grintsova O, Maier W, Mielck A. Inequalities in health care among patients with type 2 diabetes by individual socio-economic status (SES) and regional deprivation: a systematic literature review. Int $J$ Equity Health. 2014;13(1):43.

5. Jaffiol C, Thomas F, Bean K, Jégo B, Danchin N. Impact of socioeconomic status on diabetes and cardiovascular risk factors: results of a large French survey. Diabetes Metab. 2013;39(1):56-62.

6. Bäz L, Müller N, Beluchin E, et al. Differences in the quality of diabetes care caused by social inequalities disappear after treatment and education in a tertiary care centre. Diabet Med. 2012;29(5): 640-645.

7. van der Meer JB, Mackenbach JP. The care and course of diabetes: differences according to level of education. Health Policy. 1999;46(2): 127-141.

8. Brown AF, Ettner SL, Piette J, et al. Socioeconomic position and health among persons with diabetes mellitus: a conceptual framework and review of the literature. Epidemiol Rev. 2004;26(1):63-77.

9. Donabedian A. The quality of care. How can it be assessed? JAMA. 1988;260(12):1743-1748.

10. Millett C, Dodhia H. Diabetes retinopathy screening: audit of equity in participation and selected outcomes in South East London. J Med Screen. 2006;13(3):152-155.

11. Wong KW, Ho SY, Chao DV. Quality of diabetes care in public primary care clinics in Hong Kong. Fam Pract. 2012;29(2):196-202.

12. Stringhini S, Spencer B, Marques-Vidal P, et al. Age and gender differences in the social patterning of cardiovascular risk factors in Switzerland: the CoLaus study. PLoS ONE. 2012;7(11):e49443.

13. Guessous I, Gaspoz JM, Theler JM, Wolff H. High prevalence of forgoing healthcare for economic reasons in Switzerland: a population-based study in a region with universal health insurance coverage. Prev Med. 2012;55(5):521-527.

14. Peytremann-Bridevaux I, Bordet J, Zuercher E, Burnand B. Caractéristiques Des Patients Diabétiques Vaudois et Évaluation de Leur Prise En Charge: Rapport Final. Lausanne: Département universitaire de médecine et santé communautaires du Centre hospitalier universitaire vaudois; 2013. Available from: http://www.iumsp.ch/ Publications/pdf/rds211_fr.pdf. Accessed October 1, 2014.

15. Bradley C, Todd C, Gorton T, Symonds E, Martin A, Plowright R. The development of an individualized questionnaire measure of perceived impact of diabetes on quality of life: the ADDQoL. Qual Life Res. 1999;8(1-2):79-91.

16. Ware J Jr, Kosinski M, Keller SDA. A 12-Item Short-Form Health Survey: construction of scales and preliminary tests of reliability and validity. Med Care. 1996;34(3):220-233. 
17. Samsa G, Edelman D, Rothman ML, Williams GR, Lipscomb J, Matchar D. Determining clinically important differences in health status measures: a general approach with illustration to the Health Utilities Index Mark II. Pharmacoeconomics. 1999;15(2):141-155.

18. Gnavi R, Picariello R, la Karaghiosoff L, Costa G, Giorda C. Determinants of quality in diabetes care process: the population-based Torino Study. Diabetes Care. 2009;32(11):1986-1992.

19. Jotkowitz AB, Rabinowitz G, Raskin Segal A, Weitzman R, Epstein L, Porath A. Do patients with diabetes and low socioeconomic status receive less care and have worse outcomes? A national study. Am J Med. 2006;119(8):665-669.

20. Mühlhauser I, Overmann H, Bender R, et al. Social status and the quality of care for adult people with type I (insulin-dependent) diabetes mellitus - a population-based study. Diabetologia. 1998;41(10): 1139-1150.

21. Hippisley-Cox J, O'Hanlon S, Coupland C. Association of deprivation, ethnicity, and sex with quality indicators for diabetes: population based survey of 53,000 patients in primary care. BMJ. 2004;329(7477): 1267-1269.
22. Ayalon L, Gross R, Tabenkin H, Porath A, Heymann A, Porter B. Determinants of quality of life in primary care patients with diabetes: implications for social workers. Health Soc Work. 2008;33(3): 229-236.

23. Hosseini Nejhad Z, Molavi Vardanjani H, Abolhasani F, Hadipour M, Sheikhzadeh K. Relative effect of socio-economic status on the healthrelated quality of life in type 2 diabetic patients in Iran. Diabetes Metab Syndr. 2013;7(4):187-190.

24. Ejiogu N, Norbeck JH, Mason MA, Cromwell BC, Zonderman AB, Evans MK. Recruitment and retention strategies for minority or poor clinical research participants: lessons from the Healthy Aging in Neighborhoods of Diversity across the Life Span study. Gerontologist. 2011;51(Suppl 1):S33-S45.

25. Firmann M, Mayor V, Vidal PM, et al. The CoLaus study: a populationbased study to investigate the epidemiology and genetic determinants of cardiovascular risk factors and metabolic syndrome. BMC Cardiovasc Disord. 2008;8(1):6.

\section{Publish your work in this journal}

The International Journal of General Medicine is an international, peer-reviewed open-access journal that focuses on general and internal medicine, pathogenesis, epidemiology, diagnosis, monitoring and treatment protocols. The journal is characterized by the rapid reporting of reviews, original research and clinical studies across all disease areas.
A key focus is the elucidation of disease processes and management protocols resulting in improved outcomes for the patient. The manuscript management system is completely online and includes a very quick and fair peer-review system. Visit http://www.dovepress.com/ testimonials.php to read real quotes from published authors. 